\title{
The Development of Students' Spatial Orientation Through the Use of 3D Graphics
}

\author{
Benjamín Maraza-Quispe \\ Facultad de Ciencias de la Educación \\ Universidad Nacional de San Agustín de Arequipa, Arequipa-Perú
}

\begin{abstract}
The purpose of this research is to determine to what extent the use of $3 \mathrm{D}$ graphics in the educational process improves the spatial orientation skills of secondary school students. The research follows a qualitative approach of experimental type, the population is constituted by 300 students of Secondary Education of which through a simple random sampling 25 students were chosen. Four sessions of 50 minutes each have been developed, in which three-dimensional models were used, in order to determine if spatial skills are developed. A psychometric pre-test and post-test of spatial reasoning was taken in order to determine how much the spatial skills of the selected sample members are developed based on the measurement of five criteria: Construction of three-dimensional objects (intermediate level), Construction of three-dimensional objects (advanced level), Rotation of objects from references (intermediate level), Rotation of objects from references (advanced level) and deconstruction of three-dimensional objects. For the data analysis, the data from the scores obtained by the students in both the pre-test and the post-test are processed. The results allow us to visualize that the use of $3 D$ graphics in the teaching-learning processes allows us to improve spatial orientation skills to a great extent. The result is evidenced in the increase of the total scores obtained in the post-test in comparison with the results of the pre-test. Likewise, an increase from $47.9 \%$ to $75.1 \%$ of items answered correctly was observed on average, which was corroborated with the Student's t-test that gave a $P$ value of less than 0.05 , demonstrating the reliability of the research developed and therefore significantly improving spatial orientation skills in students through the use of 3D graphics technology.
\end{abstract}

Keywords-Orientation; reasoning; spatial; technology; $3 D$ graphics; education; processes; educational

\section{INTRODUCTION}

Technology is developing by leaps and bounds, expanding to several areas, such as education, where more and better technological tools are required to facilitate the learning process of students. The research revolves around the question, to what extent does the use of 3D graphics technology allow the development of spatial orientation in secondary school students?

The importance of the research lies in the impact of the use of 3D graphics in the field of education, allowing students to develop their spatial orientation, which will be useful to have a better performance in a given space and at the same time promote the use of 3D technology in educational institutions, since, the main problem of many of them and education in general is that the use of new technologies have not been widely developed, on the contrary, monotonous and routine teaching models are still used, leading to student fatigue, as well as low academic performance and attraction, since the new generations are increasingly connected with technology [1].

It is considered that virtual reality in conjunction with $3 \mathrm{D}$ models not only allows a dynamic interaction, but also a sense of immersion. Thus, it is possible to greatly enhance all engineering concepts, where spatial skills are of great importance [2]. Also, 3D models generate a sense of immersion in students because they facilitate direct interaction with objects, improving spatial orientation skills in users, important concepts in areas such as engineering or medicine. In other words, the development of spatial orientation concepts (such as spatial positioning) is possible because of the immersion provided by the manipulation of three-dimensional models.

Also, 3D models are considered to allow the analysis and visualization of the smallest details of figures and spaces, in such a way that educational software produces an improvement in perspectives [3]. According to [4] cited by [5] a person manipulates a physically solid 3D object and rotates it, the rotations made in the hand are so fast, unconscious, and inaccurate that a formal reflection of such actions can hardly be made. However, in 3D software it is possible to constrain the direction of rotation and forces students to envision various strategies with respect to the motion and anticipate the final result of the transformation.

In short, having a 3D object allows for accurate and precise manipulation of the object. In addition, by continuously manipulating the 3D model, spatial orientation is developed, so that it is possible to determine the final position of the $3 \mathrm{D}$ model after a rotation before it is made. The latter is possible because the individual's brain quickly finds a reference point and forms a model of the object in his brain and mentally rotates it using the reference point.

Similarly, a study conducted by mathematics teachers in Colombia [5] on the effectiveness of a computer environment in the development of spatial skills yielded positive results. This consisted in the creation of a software for the representation of three-dimensional objects, described as follows: The first application elaborated for the development of spatial visualization is the software called cubes and cubes which corresponds to a micro world for the teaching and learning of spatial geometry by means of computational technologies. This educational software offers the possibility of 
exploring space and three-dimensional objects in a novel and totally interactive way. Cubes and cubes allows the development of spatial visualization, perspective management and the ability to calculate volumes of irregular solids.

A clear example where the use of spatial skills is put into practice is the software activity called: "build a solid given the views", which aims to build a solid with the cubes, based on information from the top, side and front views of the result to be obtained.

This work is focused on developing spatial skills, which was achieved through the implementation of a software (cubes and cubes), which presented activities in which the students needed to locate reference points in order to carry out the constructions, for which they were given stimuli (profiles of the object to be built); in this way, the brain is trained to locate reference points and locate themselves in the environment easily.

On the other hand, in 2013 a study [6] (p.598) entitled: Three-Dimensional Sinus Imaging as an Adjunct to TwoDimensional Imaging to Accelerate Education and Improve Spatial Orientation was developed, where three-dimensional images were implemented to two-dimensional images related to the study of otorhinolaryngology to improve the spatial orientation of students during a surgical process; this study concluded satisfactorily. The results of this study indicate that the addition of a 3-D educational module to traditional 2-D training significantly improves understanding of the anatomy and spatial orientation of the paranasal sinuses and surrounding structures. This finding adds to the growing body of literature supporting 3-D modeling and simulation as a positive contribution to education.

The three-dimensional images complemented the twodimensional images by improving the spatial orientation of the students in relation to the paranasal sinuses. This was achieved because, by manipulating the three-dimensional images, the student was able to explore in more detail the concepts offered by the 2D image; thus, their spatial orientation was improved. Likewise, the improvement is evidenced in the results of a test, where the students who manipulated 3D images obtained better grades than the control group that only used images.

\section{State OF THE ART}

\section{A. 3D Modeling}

$3 \mathrm{D}$ modeling is the process of constructing an object represented by a collection of points in three-dimensional space. "A 3D prototype requires two components: modeling and texturing. Using software, such as AutoCAD MAYA and Google SketchUp, any physical object can be modeled [7] (p. 8). Furthermore, 3D modeling is defined as the representation of objects in three dimensions ( $\mathrm{X}, \mathrm{Y}$ and $\mathrm{Z}$ ). More specifically, modeling, is a process of creating a mathematical representation of surfaces using geometry [8]. Three-dimensional modeling is the process that allows the virtual formation of a physical object using software that has as its basis the three-dimensional coordinate system $(\mathrm{X}, \mathrm{Y}, \mathrm{Z})$, in which points are placed "strategically" located that will be part of the 3D model of the desired physical object.

\section{B. Three-dimensional Coordinate System}

It is considered as, "a reference system formed by three straight lines or coordinate axes that intersect at a point called origin and a unit of measurement, these three lines are also called Cartesian coordinates, with respect to the XYZ system" [9] (p.6). A 3D image is modeled by means of an XYZ coordinate system (which starts from an origin), since this system, in addition to providing a height and width, allows to give it a depth. Consequently, this reference system becomes the basis of the three-dimensional image.

\section{3D graphics}

Three-dimensional (3D) computer graphics, similar to twodimensional or vector graphics, is a branch of computer-aided visualization. Their distinction is the ability to view threedimensional (depth) data for the following conversion into two-dimensional static images or dynamic videos [10] (p.1). Three-dimensional images may resemble two-dimensional images, but the former have a unique feature, which is depth. Therefore, this feature gives the model the quality of being able to be rotated in space about its respective axis.

\section{Spatial Location and Intuitive Trajectory}

According to Newcombe \& Huttenlocher cited in [11] spatial location and intuitive trajectory can be understood as the development of mental evocations that involve elaborating two reference systems: the one based on internal cues and the one based on external cues. Both systems are constructed from the point of view of personal position (p.123). Likewise, there are two types of cues that aid spatial orientation. The first type of cues is symbolic in nature need to be semantically processed, moreover, they are usually arrows or other symbolic cues such as direction words that refer to spatial locations. While the other signals are exogenous, i.e., of explicit character and appear peripherally in the same place [12].

Both authors agree that, in order to be able to locate oneself in a space, it is necessary to build reference systems, which are divided into two types, implicit and explicit. They conclude that these need to be processed by the brain in order to reach a correct spatial location.

\section{E. Spatial Perception}

The ability to be able to recreate the image of an object and manipulate it mentally has a significant practical application in fields such as mathematics, physics, architecture or engineering. This ability, known as Spatial Perception, is the most important of all those that an individual must possess for the practice of engineering [2] (p. 2).

In addition, spatial perception is an ability that allows people to recreate and manipulate an object mentally. Likewise, this is achieved by considering reference points of the object to be recreated.

\section{F. Spatial Organization}

According to [11] this concept refers to the development of spatial perspective and spatial trajectories in non-close environments. The development of spatial perspective consists of the construction of conical reference systems using reference points extensive to the person, with which he/she can locate and locate objects or places (p. 123). Likewise, [13] mentions 
that: The spatial organization of the child evolves from: an egocentric location, in which the child does not distinguish the space occupied by his body, with that occupied by the objects around him and an objective location in which the child is able to discriminate the space occupied by his body and by each object (p. 7).

In short, spatial organization is an ability that allows people to locate themselves in a certain space, through the construction of reference systems based on egocentric location, so that the individual is located as the center of a certain space, around which objects are found.

\section{G. Spatial Structuring}

This concept refers to the understanding of spatial relationships that are represented using Euclidean or polar coordinates in two-dimensional or three-dimensional planes, which can represent locations or trajectories of objects in certain points of the plane or space [11] (p. 124). That is, spatial structuring consists of situating an object or body in function with a given perspective, as are the chordates; in this concept the individual does not refer to his own body in this same one.

\section{H. Space Channels}

According to [13], the finding of dependent spatial channels in the visual search task raises some general questions about the visual search paradigm in particular and visual processing in general. As mentioned in the introduction, the visual search paradigm seems to be one in which the subject is encouraged to treat spatial channels as independent since the spatial (see Table I).

TABLE I. SPATIAL ChanNELS. AdAPTED From [13]

\begin{tabular}{|l|l|}
\hline Visual & $\begin{array}{l}\text { The most used in all facets of life. The factors on which the } \\
\text { perception of an object depends are: magnitude, novelty, } \\
\text { repetition, isolation, intensity and movement. }\end{array}$ \\
\hline Kinesiological & $\begin{array}{l}\text { Muscle and joint receptors report the position of our body } \\
\text { in a space. }\end{array}$ \\
\hline Touch & $\begin{array}{l}\text { We perceive the sensations of the environment through } \\
\text { skin contact. }\end{array}$ \\
\hline Auditory & $\begin{array}{l}\text { Although with a more temporary component, it is very } \\
\text { important especially in children with vision problems. }\end{array}$ \\
\hline Memory & $\begin{array}{l}\text { In the absence of sight, we can memorize and reproduce } \\
\text { paths in space. }\end{array}$ \\
\hline Labyrinth & $\begin{array}{l}\text { Thanks to it, we always know the position of our head and } \\
\text { body in space. }\end{array}$ \\
\hline
\end{tabular}

\section{METHODOLOGY}

\section{A. Objective of the Research}

To determine the extent to which 3D graphics improve spatial orientation skills in secondary school students.

\section{B. Research Hypothesis}

The use of 3D graphics improves orientation skills in secondary school students.

\section{Sample Population}

The population is constituted by 300 students of which 25 students were chosen through a simple random sampling, where the choice is random because it is desired to avoid errors when choosing students who have ample spatial skills. Four sessions of fifty minutes each have been developed in the subject of Educational Technology, in which three-dimensional models will be used, in order to determine if they are useful for the development of spatial skills.

\section{Data Collection Techniques and Instruments}

The main data collection instrument is the psychometric test of spatial reasoning standardized by [14] to obtain reliable results. This test is structured as shown in Table II.

TABLE II. PSYCHOMETRIC TEST OF SPATIAL REASONING

\begin{tabular}{|l|l|}
\hline Psychometric test of spatial reasoning & Score \\
\hline Criteria & 8 \\
\hline $\begin{array}{l}\text { Criterion 1: Construction of three-dimensional objects } \\
\text { (Intermediate level) }\end{array}$ & 8 \\
\hline $\begin{array}{l}\text { Criterion 2: Construction of three-dimensional objects } \\
\text { (Advanced level) }\end{array}$ & 8 \\
\hline Criterion 3: Rotation of objects from references (Medium level) & 8 \\
\hline $\begin{array}{l}\text { Criterion 4: Rotation of objects from references (Advanced } \\
\text { Level) }\end{array}$ & 8 \\
\hline Criterion 5: deconstruction of three-dimensional objects & 40 \\
\hline Total & \\
\hline
\end{tabular}

\section{PROCEDURE}

A psychometric pre-test was taken in order to determine how developed the spatial skills of the project participants are. For the visualization, students are asked to run the 3D Builder program, then the acquired 3D models are shared with them and they are given a certain amount of time to manipulate them, then the students are asked to place the object in a certain position and determine a final position, they are also asked to draw the object from different perspectives. Then, the psychometric post-test of spatial reasoning is applied, with the objective of analyzing the effectiveness of the images for the development of spatial skills. For the data analysis, data will be collected from the grades obtained by the students.

\section{DATA ANALYSIS AND INTERPRETATION}

\section{A. Data Analysis by Criteria}

Fig. 1 shows that in a pre-test no participant achieved a maximum score ( 8 points); however, the best score was 7 , which represents $12 \%$ of the sample; and a minimum score of 2. In addition, only $56 \%$ of the sample exceeded 4 correctly marked questions.

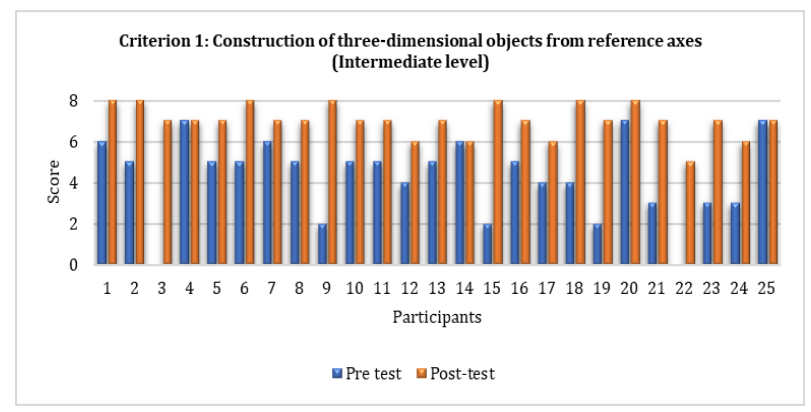

Fig. 1. Construction of Three-Dimensional Objects from Reference Axes (Intermediate Level). 
From these data it can be inferred that, at the beginning, half of the students do not have developed the ability to construct three-dimensional objects, which is achieved through spatial orientation, since reference points are considered, and the image is formed in the mind.

Fig. 2 in the case of the second criterion, presents exercises similar to the previous one, but with a higher difficulty, it is evident that, in the pre-test, only $26 \%$ of the participants exceeded $50 \%$ of correct answers to the questions, due to the difficulty of the exercises. This is understandable considering that, as the difficulty of the exercises increases, the number of correct answers of the participants is reduced; demonstrating once again that spatial orientation skills were not previously fully developed. Therefore, in the post-test, although many exceed half of the correct answers, the scores are not high compared to the previous criterion.

According to Fig. 3, in the pre-test only $28 \%$ of the sample exceeded half of the answers marked correctly, in addition to the fact that there are marks that are too low. This shows a very low development of the criterion of mental rotation of objects.

The low scores are due to the fact that this criterion is not constantly worked on, given that in daily life it is rarely encountered [15].

Subsequently, in the post-test an increase in the ability of the participants was observed, going from a percentage of $26 \%$ to $80 \%$ of students who correctly marked more than half of the questions of criterion 3. This was achieved through the manipulation of three-dimensional objects and mental exercises, such as predicting the final position of the object after a turn [16] (p. 2).

Fig. 4 shows that the participants still have low scores in the pre-test, since only $38 \%$ marked correctly more than half of the questions.

However, compared to the previous criterion, which is relatively easier, in this case there is a higher percentage of students who scored more than half of the questions correctly. This is due to the fact that the previous exercises could have served as a previous practice that allowed them to improve in these scores.

Subsequently, there is evidence of progress in the students' grade point average, which is obtained through the manipulation of three-dimensional objects throughout the sessions.

Fig. 5 shows that in the pre-test $20 \%$ of the sample marked correctly more than half of the questions, demonstrating a deficiency in the criterion of mental deconstruction of threedimensional objects to two-dimensional planes. This is due to the fact that this skill is rarely put into practice, so that there is no mastery of it. Likewise, after the exercises and in the posttest, in $\mathrm{m}$ any cases there is no evidence of a considerable improvement in the results, since, in order to completely improve this skill, many more sessions and constant practice would be required.

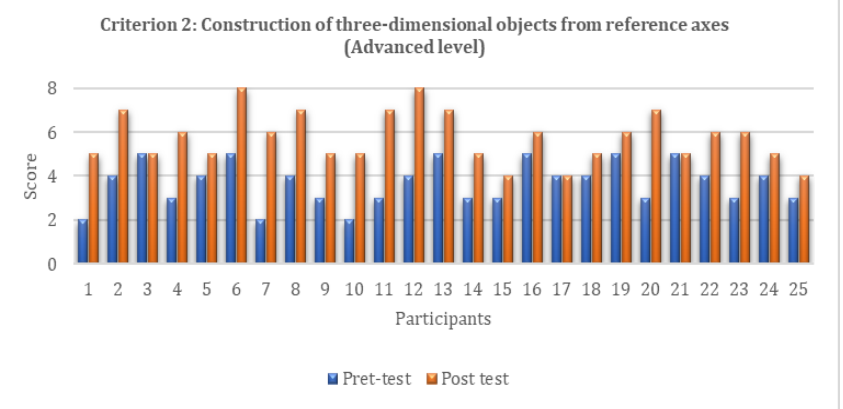

Fig. 2. Criterion 2: Construction of Three-dimensional Objects (Advanced Level).

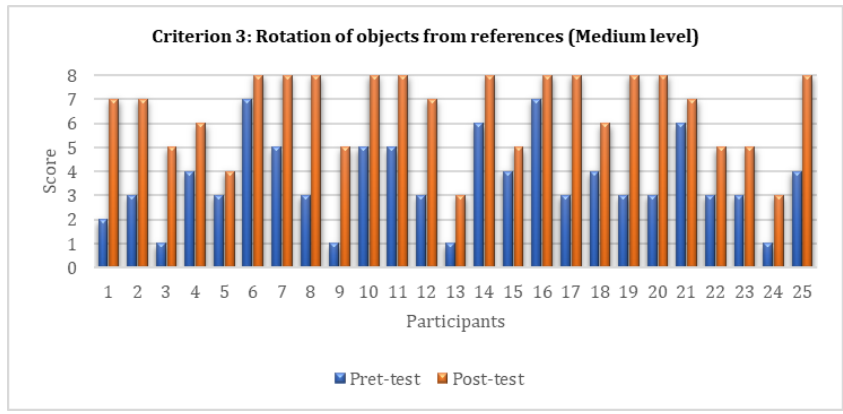

Fig. 3. Criterion 3: Rotation of Objects from References (Medium Level).

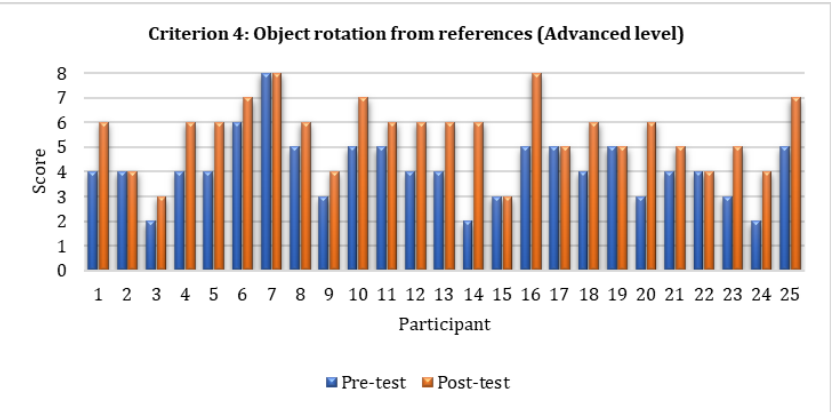

Fig. 4. Criterion 4: Rotation of Objects from References (Advanced Level).

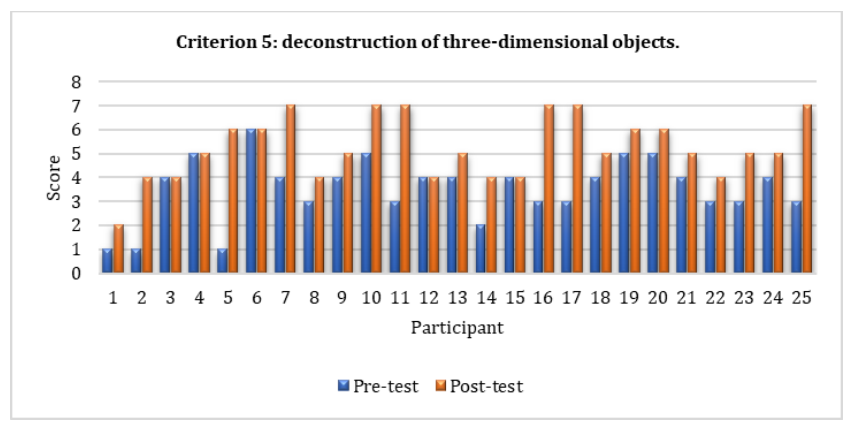

Fig. 5. Criterion: Deconstructions of Three-dimensional Objects.

\section{B. Global Data Analysis}

In Table III, in the global analysis of the results of both the pre-test and post-test, significant differences can be seen in both results, which we will analyze through the Histogram and Polygon of Frequencies. 
TABLE III. TOTAL SCORES (OUT OF 40 POINTS)

\begin{tabular}{|c|c|c|}
\hline Participants & Pre-test & Post-test \\
\hline 1 & 15 & 28 \\
\hline 2 & 17 & 30 \\
\hline 3 & 12 & 24 \\
\hline 4 & 23 & 30 \\
\hline 5 & 17 & 28 \\
\hline 6 & 29 & 37 \\
\hline 7 & 25 & 36 \\
\hline 8 & 20 & 32 \\
\hline 9 & 13 & 27 \\
\hline 10 & 22 & 34 \\
\hline 11 & 21 & 35 \\
\hline 12 & 19 & 31 \\
\hline 13 & 19 & 28 \\
\hline 14 & 19 & 29 \\
\hline 15 & 16 & 24 \\
\hline 16 & 25 & 36 \\
\hline 17 & 19 & 30 \\
\hline 18 & 20 & 30 \\
\hline 19 & 20 & 32 \\
\hline 20 & 21 & 35 \\
\hline 21 & 22 & 29 \\
\hline 22 & 14 & 24 \\
\hline 23 & 15 & 26 \\
\hline 24 & 14 & 23 \\
\hline 25 & 22 & 33 \\
\hline
\end{tabular}

According to Fig. 6 in the polygon, $40 \%$ of the participants have grades that exceed half, while the lowest grade is 12/40, demonstrating that although there are students who have developed spatial skills; there is also a percentage of $48 \%$ who do not have very developed these skills [17].

Table IV shows that 8 students obtained a score between 29 and 32 points in the post-test, which represents $32 \%$ of a total of 25 students.

According to Fig. 7, it is evident that the minimum score was 23 out of a total of 40, while the highest percentage of scores belongs to the interval [29-32[which denotes an improvement in the student's spatial location skills. Since the average improved by 10 more correct scores.

Fig. 8 shows that there is a clear increase in the number of questions answered correctly. Likewise, the Post-Test graph is similar in shape to the Pre-Test graph. This would be due to the fact that the students were able to develop their spatial skills simultaneously, highlighting that they received the learning almost evenly, since most of them showed similar progress, based on the pre-test.

According to the results observed in Tables 5 and 6, the researcher's hypothesis has been validated, which mentions that the use of images and three-dimensional models allows improving the development of orientation skills in students. This is due to the fact that the P value is less than 0.05 , so that the null hypothesis is rejected. Thus, it is concluded that the hypothesis proposed in this work is correct.

Studies have reported that spatial capabilities can be used to effectively predict the performance of individuals in performing complex operations [18].

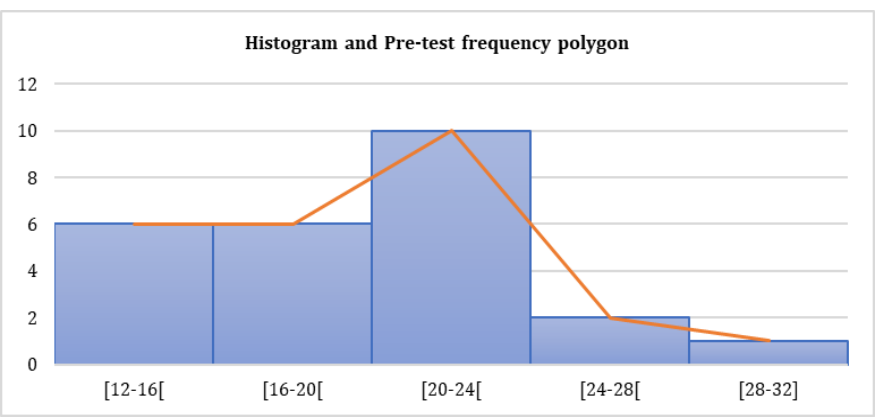

Fig. 6. Histogram and Polygon of Frequencies Pre-test.

TABLE IV. Post-TeSt FREQUenCy TABLE

\begin{tabular}{|l|l|l|l|l|}
\hline \multicolumn{6}{|l|}{ POST-TEST FREQUENCY TABLE } \\
\hline Notes & f & F & fi & Hi \\
\hline$[23-26[$ & 4 & 4 & 0,16 & 0,16 \\
\hline$[26-29[$ & 5 & 9 & 0,2 & 0,36 \\
\hline$[29-32[$ & 8 & 17 & 0,32 & 0,68 \\
\hline$[32-35[$ & 3 & 20 & 0,12 & 0,80 \\
\hline$[35-38]$ & 5 & 25 & 0,2 & 1,00 \\
\hline $\mathrm{N}$ & 25 & & 1.00 & \\
\hline
\end{tabular}

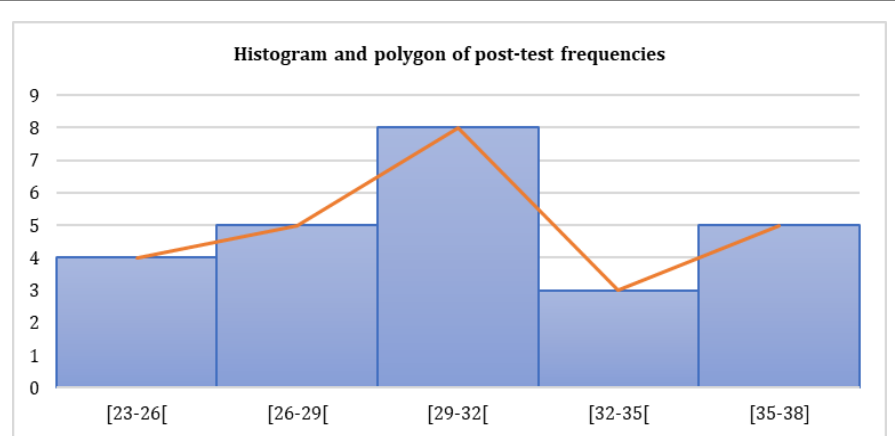

Fig. 7. Histogram and Polygon of Frequencies Post-test.

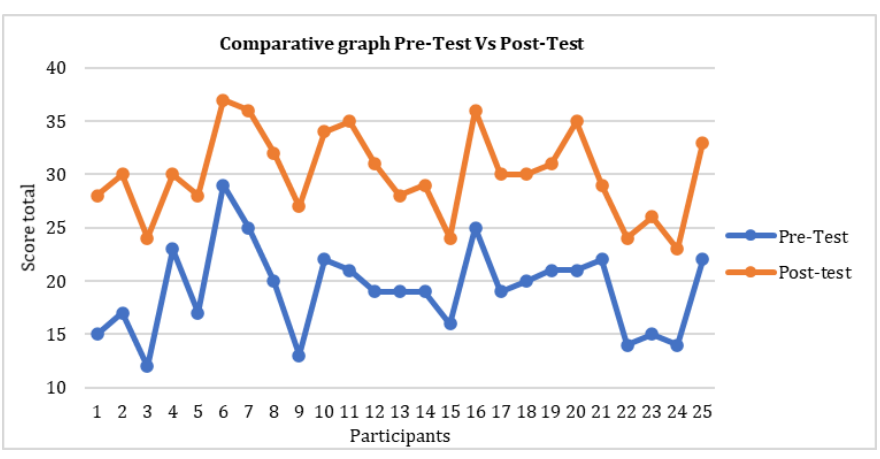

Fig. 8. Comparison between Pre-test and Post-test. 
TABLE V. VALIDATION OF STUDENT'S T HYPOTHESIS

\begin{tabular}{|l|l|}
\hline Steps & Procedure \\
\hline $\begin{array}{l}\text { Hypothesis } \\
\text { formulatio } \\
\mathbf{n}\end{array}$ & $\begin{array}{l}\text { In this part, two hypotheses are presented: the null hypothesis } \\
\text { (H0) and the researcher's hypothesis (H1). } \\
\text { H0=The use of 3D graphics does not improve the development } \\
\text { of orientation skills in students. } \\
\text { H1=The use of 3D graphics improves the development of } \\
\text { orientation skills in students. }\end{array}$ \\
\hline $\begin{array}{l}\text { Significanc } \\
\text { e level }\end{array}$ & $\begin{array}{l}\text { It is a numerical value that is defined as the probability of } \\
\text { making the decision to reject the null hypothesis. This value is } \\
5 \% \text { or 0.05\%. }\end{array}$ \\
\hline $\begin{array}{l}\text { Choice of } \\
\text { statistical } \\
\text { test }\end{array}$ & $\begin{array}{l}\text { In this case we have the Pre-test (Variable 1) and the Post-test } \\
\text { (Variable 2). }\end{array}$ \\
\hline $\begin{array}{l}\text { p-value } \\
\text { estimation }\end{array}$ & $\begin{array}{l}\text { The Excel data analysis tool is used in which the T-test option } \\
\text { for paired two-sample means is selected. }\end{array}$ \\
\hline $\begin{array}{l}\text { Decision } \\
\text { making }\end{array}$ & $\begin{array}{l}\text { If p<0.05 then the Null hypothesis is rejected and the } \\
\text { researcher hypothesis is accepted. } \\
\text { If p>0.05, the null hypothesis is accepted and the research } \\
\text { hypothesis is rejected. }\end{array}$ \\
\hline
\end{tabular}

TABLE VI. P-VALUe Estimation

\begin{tabular}{|l|l|l|}
\hline & Variable 1 & Variable 2 \\
\hline Media & 19.1600 & 30.04 \\
\hline Variance & 17.0567 & 16.70666667 \\
\hline Pearson correlation coefficient & 0.8758 & - \\
\hline Hypothetical difference of means & 0.0000 & - \\
\hline Degrees of freedom & 24.0000 & - \\
\hline Statistic t & -26.5656 & - \\
\hline P(T<=t) one tail & 0.0000 & - \\
\hline Critical value of t (one-tailed) & 1.7109 & - \\
\hline P(T<=t) two-tailed & 0.0000 & - \\
\hline Critical value of $\mathbf{t}$ (two-tailed) & 2.0639 & - \\
\hline
\end{tabular}

\section{FUtURE RESEARCH SCOPES}

The future scope of the research involves experimentation with a larger population using more indicators with a qualitative approach where behaviors, qualities and attitudes can be observed in order to obtain reliable data. According to [19] visualization, as both the product and the process of creation, interpretation and reflection upon pictures and images, is gaining increased visibility in mathematics and mathematics education.

Currently the need to provide quality education to future generations has led to the development of new teaching methodologies; within this fact the tools provided by information technologies have been positioned as the future of learning [20].

\section{DISCUSSION AND CONCLUSIONS}

The use of 3D graphics in the teaching-learning processes allows improving the spatial orientation skills of the students to a great extent. This result is evidenced by the increase in the total scores obtained in the Post-test compared to the results of the Pre-test. Also, specifically, it was observed, on average, an increase from $47.9 \%$ to $75.1 \%$ of questions answered correctly, which in conjunction with the Student's t-test that gave a $\mathrm{P}$ value less than 0.05 demonstrating the reliability of the study and therefore the significant improvement of spatial orientation skills in students. On the other hand, criterion 2 shows the greatest increase in the students' scores, because the manipulation and rotation of objects was an activity that was performed in all learning sessions.

3D graphics can be used in several educational areas, in order to improve people's spatial skills. Likewise, it is considered that in order to improve spatial skills it is necessary to practice constantly, since it is necessary to put spatial skills into practice, taking into account that they are part of the multiple intelligences of people, specifically in spatial intelligence. In addition, spatial skills are very important in the training of professionals in areas such as engineering or architecture, which is why many universities take exams in relation to this type of skills.

Likewise, in order for students to efficiently develop spatial skills, such as spatial orientation, it is necessary for them to have a clear understanding of digital citizenship, so that they can handle technology in an appropriate and responsible manner. In addition, proper supervision by teachers must be carried out.

\section{ACKNOWLEDGMENT}

The research was made possible thanks to the support of the Universidad Nacional de San Agustín de Arequipa through UNSA INVESTIGA.

\section{REFERENCES}

[1] Maraza-Quispe, B., Alejandro-Oviedo, O., Choquehuanca-Quispe, W. (2020). Towards a Standardization of Learning Behavior Indicators in Virtual Environments. International Journal of Advanced Computer Science and Applications, Vol. 11, No. 11. From https://thesai.org/Downloads/Volume11No11/Paper_19Towards_a_Standardization_of_Learning_Behavior.pdf.

[2] Suárez Quiróz, J., Rubio García, R., Gallegos Santos, R., \& Gonzáles, M. (2004). Development of a trainer for spatial perception based on virtual reality using public domain technologies. Sustainability 2018, 10, 1074; doi:10.3390/su10041074.

[3] Nurbekova, Z., Grinshkun, V., Aimicheva, G., Nurbekov, B. \& Tuenbaeva, K. (2020). Project-Based Learning Approach for Teaching Mobile Application Development Using Visualization Technology. International Journal of Emerging Technologies in Learning (iJET), 15(8), 130-143. Kassel, Germany: International Journal of Emerging Technology in Learning. from https://www.learntechlib.org/p/217072/.

[4] Gutierrez , A., Pegg, J., \& Lawrie, C. (2004). Characterization of Students' Reasoning and Proof Abilities in 3-Dimensional Geometry. ERIC. Proceedings of the 28th Conference of the International Group for the Psychology of Mathematics Education, Vol 2 pp 511-518.

[5] Hoyos Salcedo, E. A., \& Acosta MInoli, C. A. (2014). Improvement of spatial visualization skills through the use of a computer environment. XV Virtual Educa Peru Meeting.

[6] Yao WC, Regone RM, Huyhn N, Butler EB, Takashima M. (2014). Three-dimensional sinus imaging as an adjunct to two-dimensional imaging to accelerate education and improve spatial orientation. Laryngoscope. Mar;124(3):596-601. doi: 10.1002/lary.24316. Epub 2013 Oct 2. PMID: 23881572.

[7] Torres, C. E., \& Rodríguez Carrilo, J. (2019). Immersive learning environments and teaching to cyber generations. vol.45, e187369. ISSN 1678-4634. https://doi.org/10.1590/s1678-4634201945187369. 
[8] Ortega, A. J. (2016). Digital Fabrication: Introduction to 3D modeling and printing. Ministerio de Educacion, Cultura y Deporte. Colección Aula Mentor. https://sede.educacion.gob.es/publiventa.

[9] Charro Arévalo, C., \& Valencia Armijos, V. (2007). Three-dimensional model of the geological history of Cotipaxi Volcano. Ecuador.

[10] Pytlík, M., \& Kostolányová, K. (2018). 3D technologies in education. AIP Conference Proceedings. doi:https://doi.org/10.1063/1.5079085.

[11] Zapateiro Segura, J. C., Poloche Arango, S. K., \& Camargo Uribe, L. (2017). Spatial orientation: a teaching and learning path focused on locations and trajectories. TED, 18.

[12] Ouellet, M., Santiago, J., Funes, M., \& Lupiañez, J. (1999). Spatial orientation of attention using temporal concepts. 36(1), 17-24. https://doi.org/10.1037/a0017176.

[13] Pollatsek, A. and Digman, L. (2020) Dependent spatial channels in visual processing, Cognitive Psychology, Volume 9, Issue 3, Pages 326352, ISSN 0010-0285, https://doi.org/10.1016/0010-0285(77)90011-1.

[14] Maraza-Quispe, B., Alejandro-Oviedo, O., Fernández-Gambarini, W., Cisneros-Chavez, B., \& Choquehuanca-Quispe, W. (2020). Analysis of YouTube as a tool for documentary research in higher education students. Publications, 50(2), 133-147. doi:10.30827/publications.v50i2. 13949.

[15] Strong, S., \& Smith, R. (2001). Spatial visualization: fundamentals and trends in ingineering graphics. Journal of Industrial Technology. The
Official Electronic Publication of the National Association of Industrial Technology. Volume 18, Number 1 • November 2001 to January 2002.

[16] Navarro Rosa., Saorín, José Contero Manuel, Piquer and Ana Conesa, Julián. (2004). el desarrollo de las habilidades de visión espacial y croquis en la ingeniería de producto.

[17] Dastoli, C. (2018). Design, digital fabrication \& 3d printing: a crash course for design students. Conference: 10th International Conference on Education and New Learning Technologies. DOI: 10.21125/edulearn.2018.1186.

[18] Liao, KH. (2017). Las habilidades para comprender las relaciones espaciales, la orientación espacial y la visualización espacial afectan el rendimiento del diseño de productos 3D: utilizando el diseño de cajas de cartón como ejemplo. Int $\mathrm{J}$ Technol Des Educ 27, 131-147. https://doi.org/10.1007/s10798-015-9330-3.

[19] Arcavi, A. (2003). El papel de las representaciones visuales en el aprendizaje de las matemáticas. Edu. Semental. Matemáticas. 52 , 215241. https://doi.org/10.1023/A:1024312321077.

[20] Maraza-Quispe, B., Sotelo-Jump, A., Alejandro-Oviedo, O., QuispeFlores, L., Cari-Mogrovejo, L., Fernandez-Gambarini, W and CuadrosPaz, L. (2021). "Towards the Development of Computational Thinking and Mathematical Logic through Scratch" International Journal of Advanced Computer Science and Applications, 12(2), http://dx.doi.org/10.14569/IJACSA.2021.0120242. 